\title{
DEVELOPMENT OF MATHEMATICAL MODEL ON GAS TUNGSTEN ARC WELDING PROCESS PARAMETERS
}

\author{
K. Ashok Kumar ${ }^{1}$, G.Satish ${ }^{2}$, V. Lakshmi Narayana ${ }^{3}$, N. Srinivasa Rao ${ }^{4}$ \\ 1, 2, 3, 4 Assistant Professor, Mechanical Engineering Department, Shri Vishnu Engineering College For Women, Andhra \\ Pradesh, India,
}

ashokkumark@svecw.edu.in, satishg@svecw.edu.in,lakshminarayanav@svecw.edu.in,srinivasraon@svecw.edu.in

\begin{abstract}
GAS TUNGSTEN ARC WELDING (GTAW) is the quality weld process. It is preferred welding process for stainless steel, low alloy steel, nickel, cobalt, titanium, aluminum, copper, and magnesium. The present work aims to evaluate the effect of Gas Tungsten Arc Welding process parameters on the quality of the weld bead. The process parameters Welding Current, Wire Diameter, Wire Feed Speed, Ratio of wire feed rate to travel speed and Plate thickness are taken as a input variables for this present work. The quality of the weld bead can be assessed by the bead characteristics such as Penetration, Reinforcement \& Width. Experiments were conducted to study the effects of the welding process parameters. Statistically designed experiments with 5 process parameters (each at 3 levels) are conducted to study the effect of these parameters on bead geometry. It is found from the analysis of variance (ANOVA) that the wire feed rate, travel speed and wire diameter are the main parameters that influence bead geometry in GTAW. Mathematical models are developed for depth of penetration, reinforcement height and bead width for GTAW using the multiple regression analysis.
\end{abstract}

Index Terms: GTAW, DataFit version 9.0.59, I, D, WFR, TS, PT.

\section{INTRODUCTION}

Gas tungsten arc welding (GTAW), also known as tungsten inert gas (TIG) welding, is an arc welding process that uses a nonconsumable tungsten electrode to produce the weld. The weld area is protected from atmospheric contamination by a shielding gas (usually an inert gas such as argon), and a filler metal is normally used, though some welds, known as autogenous welds, do not require it. A constant-current welding power supply produces energy which is conducted across the arc through a column of highly ionized gas and metal vapors known as plasma.

GTAW process is a candidate welding process, as it produces high quality and consistent welds and provides excellent control of heat input. The GTAW process uses a non-consumable electrode protected by an inert gas. As this process uses a non-consumable electrode, extra material, if required, is added through a filler wire either manually or using a wire feeder.

GTAW is most commonly used to weld thin sections of stainless steel and non-ferrous metals such as aluminum, magnesium, and copper alloys. The process grants the operator greater control over the weld than competing procedures such as shielded metal arc welding and gas metal arc welding, allowing for stronger, higher quality welds. However, it is comparatively more complex and difficult to master, and furthermore, it is significantly slower than most other welding techniques. A related process, plasma arc welding, uses a slightly different welding torch to create a more focused welding arc and as a result is often automated. . TIG welding has become a popular choice of welding processes when high quality, precision welding is required.

GTAW is frequently referred to as TIG welding. TIG welding is a commonly used high quality welding process. TIG welding has become a popular choice of welding processes when high quality, precision welding is required.

In TIG welding an arc is formed between a non-consumable tungsten electrode and the metal being welded. Gas is fed through the torch to shield the electrode and molten weld pool. If filler wire is used, it is added to the weld pool separately.

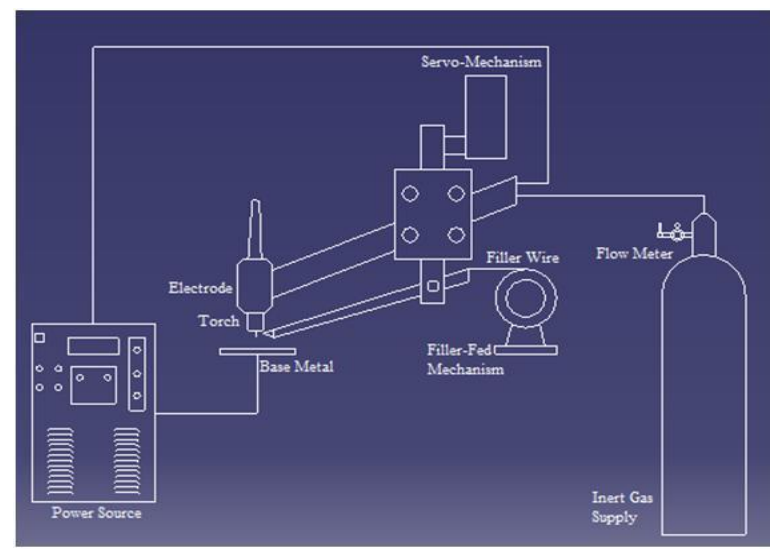

Fig -1: Automatic GTAW System setup. 
The weld-bead formed by the GTAW process plays an important role in determining the mechanical properties of the weld and its quality. The weld-bead geometry also directly affects the complexity of weld schedules. The weld-bead shape parameters such as the bead width, reinforcement height and depth of penetration, shown in Fig 2, are determined by the GTAW process parameters such as current, voltage, welding speed and wire feed rate.

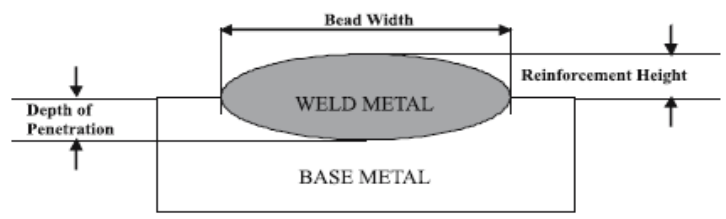

Fig - 2: Weld bead geometry.

\subsection{Statistical Design of Experiments}

A designed experiment is the simultaneous evaluation of two or more factors (parameters) for their ability to affect the resultant average or variability of particular product or process characteristics. To accomplish this in an effective and statistically proper fashion, the levels of the factors are varied in a strategic manner, the results of the particular test combinations are observed, and the complete set of results is analyzed to determine the important factors and preferred levels, and to find whether increase or decrease of those levels will potentially lead to further improvement. The initial experiments, often referred to as screening experiments, are used to find the few important, significant factors out of many possible factors involved with a product or process design. This experiment is typically a small experiment with many factors at two levels. Later rounds of experiments typically involve few factors at more than two levels to determine conditions of further improvement.

\subsection{The Phases in Design of Experiments.}

The design of experiments (DOE) process is divided into three main phases as (1) the planning phase (2) the conducting phase (3) the analyses phase.

The planning phase is by far the most important phase for the experiment to provide the expected information. An experimenter will learn the information from any experiment, sometimes in a positive sense and sometimes in a negative sense. Positive information is an indication of which factors and which levels lead to improved product or process performance. Negative information is an indication of which factors don't lead to improvement, but no indication of which factors do. If the experiment includes the real, yet unknown, influential factors, the experiment will yield negative information. In the planning phase factors and levels are selected and, therefore, it is the most important stage of experimentation. Also, the correct selection of factors and levels is nonstatistical in nature and is more dependent upon product and process expertise.

The second most important phase is the conducting phase, where test results are actually collected. If experiments are well planned and conducted, the analysis is much easier and more likely to yield positive information about factors and levels.

In the analysis phase is the positive or negative information concerning the selected factors and levels is generated based on the previous two phases. This phase is most statistical in nature of the three phases of the DOE.

\subsection{Taguchi Method.}

Although fractional factorial design allows a fraction of the total number of runs required in the factorial design, there are no general guidelines for its application or the analysis of the results obtained by performing the experiments. Taguchi's approach complements these two important areas. First, he clearly defines a set of general designs for factorial experiments that cover many applications. The special set of designs consists of orthogonal arrays (OA). The use of these arrays helps to determine the least number of experiments needed for a given set of factors. A comparison of number of experiments in factorial design and Taguchi design is presented in Table 1. Second, he devised a standard method for analysis of the results. The combination of standard experimental design techniques and analysis methods in the Taguchi approach produces consistency and reproducibility rarely found in any other statistical method.

Table -1: Comparison of Factorial design and Taguchi design

\begin{tabular}{|l|l|l|l|}
\hline Factors & Level & $\begin{array}{l}\text { Factorial design } \\
\text { Total no. of } \\
\text { experiments }\end{array}$ & $\begin{array}{l}\text { Taguchi } \\
\text { Design }\end{array}$ \\
\hline 2 & 2 & $4(22)$ & 4 \\
\hline 3 & 2 & $8(23)$ & 4 \\
\hline 4 & 2 & $16(24)$ & 8 \\
\hline 7 & 2 & $128(27)$ & 8 \\
\hline 15 & 2 & $32768(215)$ & 16 \\
\hline 4 & 3 & $81(34)$ & 9 \\
\hline 5 & 3 & $243(35)$ & 18 \\
\hline
\end{tabular}

Taguchi has established orthogonal arrays (OA) to describe a large number of experimental situations. The symbolic designation for these arrays carries the key information on the size of the experiment. For example, designated array L18 requires 18 trail runs; L9 requires 9 experiments and so on. The vertical columns of the arrays acquire a special combinatorial property i.e., in any pair of columns in an OA, all combinations of the treatment (of the two factors assigned to this pair) occur and they do so an equal number of times. This property is called the balancing property of OAs. This balancing property permits the use of simple arithmetic to 
find the effect of the experimental factors on the response under study. Taguchi has tabulated 18 basic orthogonal arrays that we call standard orthogonal arrays. The standard orthogonal arrays along with the number of columns at different levels for these arrays are listed in Table 2.

Table -2: Standard Orthogonal Arrays.

\begin{tabular}{|c|c|c|c|c|c|c|}
\hline \multirow{2}{*}{$\begin{array}{l}\text { Orthogonal } \\
\text { Array }\end{array}$} & \multirow{2}{*}{$\begin{array}{l}\text { Number } \\
\text { of } \\
\text { Rows }\end{array}$} & \multirow{2}{*}{$\begin{array}{l}\text { Maximum } \\
\text { No of } \\
\text { factors }\end{array}$} & \multicolumn{4}{|c|}{$\begin{array}{l}\text { Maximum no of } \\
\text { columns At these levels }\end{array}$} \\
\hline & & & 2 & 3 & 4 & 5 \\
\hline L4 & 4 & 3 & 3 & - & - & - \\
\hline L8 & 8 & 7 & 7 & - & - & - \\
\hline L9 & 9 & 4 & - & 4 & - & - \\
\hline L12 & 12 & 11 & 11 & - & - & - \\
\hline L16 & 16 & 15 & 15 & - & - & - \\
\hline L'16 & 16 & 5 & - & - & 5 & - \\
\hline L18 & 18 & 8 & 1 & 7 & - & - \\
\hline L25 & 25 & 6 & - & - & - & 6 \\
\hline L27 & 27 & 13 & - & 13 & - & - \\
\hline L32 & 32 & 31 & 31 & - & - & - \\
\hline L'32 & 32 & 10 & 1 & - & 9 & - \\
\hline L36 & 36 & 23 & 11 & 12 & - & - \\
\hline L'36 & 36 & 16 & 3 & 13 & - & - \\
\hline L50 & 50 & 12 & 1 & - & - & 11 \\
\hline L54 & 54 & 26 & 1 & 25 & - & - \\
\hline L64 & 64 & 63 & 63 & - & - & - \\
\hline L'64 & 64 & 21 & - & - & 21 & - \\
\hline L81 & 81 & 40 & - & 40 & - & - \\
\hline
\end{tabular}

\subsection{ANOVA Terms and Notations.}

The analysis of variance computes quantities known as degrees of freedom, sum of squares, mean squares, etc. and organizes them in a standard tabular format. These quantities and their interrelationships are defined as given below using the following notation.

$\begin{array}{lll}\mathrm{V} & = & \text { mean squares (variance) } \\ \mathrm{P} & = & \text { percent contribution } \\ \mathrm{S} & = & \text { sum of squares } \\ \mathrm{T} & = & \text { total (or results) } \\ \mathrm{S} & = & \text { pure sum of squares } \\ \mathrm{N} & = & \text { number of experiments } \\ \mathrm{f} & = & \text { degrees of freedom } \\ \mathrm{C} . \mathrm{F} & = & \text { correction factor } \\ \mathrm{e} & = & \text { error (experimental) } \\ \mathrm{n} & = & \text { total degrees of freedom }\end{array}$

\subsubsection{Variance}

The variance of each factor is determined by the sum of the square of each trial sum result involving the factor, divided by the degrees of freedom of the factor. Thus
$\mathrm{VA}=\mathrm{SA} / \mathrm{fA}$ (for factor $\mathrm{A}$ )
$\mathrm{VB}=\mathrm{SB} / \mathrm{fB}$ (for factor $\mathrm{B}$ )
$\mathrm{VC}=\mathrm{SC} / \mathrm{fC} \quad$ (for factor $\mathrm{C}$ )

$\mathrm{Ve} \quad \mathrm{e} / \mathrm{fe} \quad$ (for error terms)

\subsubsection{Variance Ratio.}

The variance ratio is the variance of the factor divided by the error variance

$\begin{array}{lll}\mathrm{FA} & = & \mathrm{VA} / \mathrm{Ve} \\ \mathrm{FB} & = & \mathrm{VB} / \mathrm{Ve} \\ \mathrm{FC} & = & \mathrm{VC} / \mathrm{Ve} \\ \mathrm{Fe} & = & \mathrm{Ve} / \mathrm{Ve}\end{array}$

\subsubsection{Pure Sum of Squares.}

The pure sum of squares is the sum minus the degrees of freedom times the error variance

$\begin{array}{lll}\text { S'A } & = & \mathrm{SA}-\mathrm{fA} \times \mathrm{Ve} \\ \text { S'B } & = & \mathrm{SB}-\mathrm{fB} \times \mathrm{Ve} \\ \text { S'C } & = & \mathrm{SC}-\mathrm{fC} \times \mathrm{Ve} \\ \text { S'"e } & = & \mathrm{Se}-(\mathrm{fA}+\mathrm{fB}+\mathrm{fC}) \mathrm{Ve}\end{array}$

\subsubsection{Percent Contribution.}

The percent contribution of each factor is the ratio of the factor sum to the total, expressed in percent

$\begin{array}{lll}\mathrm{PA} & = & \mathrm{SA} \times 100 / \mathrm{STPB} \\ & = & \mathrm{SB} \times 100 / \mathrm{ST} \\ \mathrm{PC} & = & \mathrm{SC} \times 100 / \mathrm{ST} \\ \mathrm{Pe} & = & \mathrm{Se} \times 100 / \mathrm{ST}\end{array}$

\subsection{Selection of Orthogonal Array for the Present}

\section{Work.}

In the experiments with gas tungsten arc welding, the number of factors chosen for study is 5, each at 3 levels. Each factor has degrees of freedom (DOF) of 2 (DOF = number of levels-1). Therefore the experiment under consideration has $10 \mathrm{DOF}$ and 1 DOF for overall mean. No interaction is considered between the factors. Hence the total DOF is 11 . It is required to conduct at least 11 experiments to estimate the desired effect of factors. The corresponding OA must have at least 11 rows and five 3-level columns. It can be seen from Table 3.2 that the L18 standard array meets requirements. The L18 standard orthogonal array is given in Table 3.1. It has eight columns and eighteen rows. The degree of freedom of L18 array is 18. In present work five 3-level factors are chosen. The structure of orthogonal array requires that all the 18 experiments indicated by the L18 array must be run. If one runs fewer than 18 experiments, it would not be possible to complete the analysis necessary to evaluate the desired effects. 
Table -3: L18 $(21 \times 37)$ Orthogonal Array \& its Linear Graph.

\begin{tabular}{|c|c|c|c|c|c|c|c|c|}
\hline \multirow{2}{*}{$\begin{array}{l}\text { Expt. } \\
\text { No }\end{array}$} & \multicolumn{8}{|c|}{ Column } \\
\hline & 1 & 2 & 3 & 4 & 5 & 6 & 7 & 8 \\
\hline 1 & 1 & 1 & 1 & 1 & 1 & 1 & 1 & 1 \\
\hline 2 & 1 & 1 & 2 & 2 & 2 & 2 & 2 & 2 \\
\hline 3 & 1 & 1 & 3 & 3 & 3 & 3 & 3 & 3 \\
\hline 4 & 1 & 2 & 1 & 1 & 2 & 2 & 3 & 3 \\
\hline 5 & 1 & 2 & 2 & 2 & 3 & 3 & 1 & 1 \\
\hline 6 & 1 & 2 & 3 & 3 & 1 & 1 & 2 & 2 \\
\hline 7 & 1 & 3 & 1 & 2 & 1 & 3 & 2 & 3 \\
\hline 8 & 1 & 3 & 2 & 3 & 2 & 1 & 3 & 1 \\
\hline 9 & 1 & 3 & 3 & 1 & 3 & 2 & 1 & 2 \\
\hline 10 & 2 & 1 & 1 & 3 & 3 & 2 & 2 & 1 \\
\hline 11 & 2 & 1 & 2 & 1 & 1 & 3 & 3 & 2 \\
\hline 12 & 2 & 1 & 3 & 2 & 2 & 1 & 1 & 3 \\
\hline 13 & 2 & 2 & 1 & 2 & 3 & 1 & 3 & 2 \\
\hline 14 & 2 & 2 & 2 & 3 & 1 & 2 & 1 & 3 \\
\hline 15 & 2 & 2 & 3 & 1 & 2 & 3 & 2 & 1 \\
\hline 16 & 2 & 3 & 1 & 3 & 2 & 3 & 1 & 2 \\
\hline 17 & 2 & 3 & 2 & 1 & 3 & 1 & 2 & 3 \\
\hline 18 & 2 & 3 & 3 & 2 & 1 & 2 & 3 & 1 \\
\hline
\end{tabular}

\section{DESIGN OF EXPERIMENTS.}

The process parameters selected for the present study are Welding current, wire diameter, wire feed rate, ratio of wire feed rate to travel speed, and plate thickness. The ratio of wire feed rate to travel speed (WFR/TS) is chosen as a factor instead of travel speed to avoid the erratic combinations such as high travel speed for low feed rate etc. Three levels are chosen for all the process parameters (also called factors). These selected factors and their levels are given in Table 4.

Table -4: Factors and their levels used in GTAW experiments

\begin{tabular}{|l|l|l|l|l|}
\hline Parameters & Notation & \multicolumn{3}{|l|}{ Factor Levels } \\
\cline { 3 - 5 } & 1 & 2 & 3 \\
\hline Current(A) & I & 140 & 160 & 180 \\
\hline $\begin{array}{l}\text { Wire diameter(mm) } \\
\text { diam }\end{array}$ & D & 1.2 & 1.4 & 1.6 \\
\hline $\begin{array}{l}\text { Wire feed } \\
\text { rate(mm/min) }\end{array}$ & WFR & 1500 & 2000 & 2500 \\
\hline $\begin{array}{l}\text { Ratio of wire } \\
\text { feed rate to } \\
\text { travel speed } \\
\text { (mm) WFR/TS }\end{array}$ & 6 & 8 & 10 \\
\hline Pipe thickness & PT & 8 & 12 & 16 \\
\hline
\end{tabular}

Heat input $\mathbf{J}$

$$
=\quad \frac{\text { WeI*60 }}{\text { GIS*1000 }} * \eta
$$

$$
\begin{array}{lll}
\text { Volume V1 } & = & \frac{G I S[P+\mathrm{B}] * W}{2} \\
\text { Wire deposition volume } \mathrm{V} 2 & = & \mathrm{WFR} * \Pi * \mathbb{R}^{2} \\
\text { Efficiency } \eta & = & \frac{\mathrm{V} 2}{W 1} * 100 \\
\% \text { of dilution } & = & \frac{B}{A+B} * 100
\end{array}
$$

The experimenters log after translating factors and their level values using L18 array is given in Table 5

Table -5: Experimenters log sheet for GTAW

\begin{tabular}{|l|l|l|l|l|l|}
\hline $\begin{array}{l}\text { Experi } \\
\text { m- } \\
\text { ental } \\
\text { Numb } \\
\text { er }\end{array}$ & $\begin{array}{l}\text { Curre } \\
\text { nt (A) }\end{array}$ & $\begin{array}{l}\text { Wire } \\
\text { Diamet } \\
\text { er } \\
(\mathrm{mm})\end{array}$ & $\begin{array}{l}\text { Wire } \\
\text { Feed } \\
\text { Rate } \\
(\mathrm{mm} / \\
\text { min) }\end{array}$ & $\begin{array}{l}\text { Ratio } \\
\text { of wire } \\
\text { feed } \\
\text { rate to } \\
\text { travel } \\
\text { speed }\end{array}$ & $\begin{array}{l}\text { Plate } \\
\text { Thickne } \\
\text { ss (mm) }\end{array}$ \\
\hline E01 & 140 & 1.2 & 1000 & 6 & 8 \\
\hline E02 & 140 & 1.4 & 2000 & 8 & 12 \\
\hline E03 & 140 & 1.6 & 3000 & 10 & 16 \\
\hline E04 & 160 & 1.2 & 1000 & 8 & 12 \\
\hline E05 & 160 & 1.4 & 2000 & 10 & 16 \\
\hline E06 & 160 & 1.6 & 3000 & 6 & 8 \\
\hline E07 & 180 & 1.2 & 2000 & 6 & 16 \\
\hline E08 & 180 & 1.4 & 3000 & 8 & 8 \\
\hline E09 & 180 & 1.6 & 1000 & 10 & 12 \\
\hline E10 & 140 & 1.2 & 3000 & 10 & 12 \\
\hline E11 & 140 & 1.4 & 1000 & 6 & 16 \\
\hline E12 & 140 & 1.6 & 2000 & 8 & 8 \\
\hline E13 & 160 & 1.2 & 2000 & 10 & 8 \\
\hline E14 & 160 & 1.4 & 3000 & 6 & 12 \\
\hline E15 & 160 & 1.6 & 1000 & 8 & 16 \\
\hline E16 & 180 & 1.2 & 3000 & 8 & 16 \\
\hline E17 & 180 & 1.4 & 1000 & 10 & 8 \\
\hline E18 & 180 & 1.6 & 2000 & 6 & 12 \\
\hline & & & & & \\
\hline
\end{tabular}

The absolute value of TS at different WFR/TS ratios is given below.

Table -6: Absolute value of TS at different WFR/TS ratio

\begin{tabular}{|l|l|l|l|}
\hline Ratio & 6 & 8 & 10 \\
\hline WFR/TS & \multicolumn{3}{|l|}{ Travel Speed (mm/min) } \\
\hline 1000 & 166.67 & 125 & 100 \\
\hline 2000 & 333.33 & 250 & 200 \\
\hline 3000 & 500 & 375 & 300 \\
\hline
\end{tabular}




\section{RESULTS}

From the microscopic examination we find penetration, reinforcement \& width and further calculations like percentage of dilution, heat input (J), weld bead volume (V1), wire deposition volume (V2) and wire deposition efficiency were done by using the formulas.

Table -7: Experimental results for bead geometry \& \% Dilution using L18 orthogonal array

\begin{tabular}{|l|l|l|l|l|}
\hline $\begin{array}{l}\text { Experimental } \\
\text { Number }\end{array}$ & $\begin{array}{l}\text { Penetration } \\
(\mathrm{P}) \mathrm{mm}\end{array}$ & $\begin{array}{l}\text { Reinforcement } \\
(\mathrm{R}) \mathrm{mm}\end{array}$ & $\begin{array}{l}\text { Width } \\
(\mathrm{W}) \\
\mathrm{mm}\end{array}$ & $\begin{array}{l}\text { \% of } \\
\text { Dilution }\end{array}$ \\
\hline E01 & 0.75 & 1.95 & 5.25 & 27.78 \\
\hline E02 & 0.91 & 2.26 & 7.45 & 28.13 \\
\hline E03 & 1.96 & 4.95 & 4.83 & 28.57 \\
\hline E04 & 0.82 & 1.96 & 3.22 & 28.57 \\
\hline E05 & 1.31 & 3.21 & 3.78 & 28.89 \\
\hline E06 & 2.25 & 5.14 & 10.45 & 30.67 \\
\hline E07 & 1.76 & 2.75 & 6.34 & 39.13 \\
\hline E08 & 1.91 & 3.12 & 7.22 & 38.78 \\
\hline E09 & 1.18 & 2.1 & 3.28 & 37.50 \\
\hline E10 & 0.75 & 1.95 & 7.13 & 27.78 \\
\hline E11 & 0.91 & 2.28 & 6.34 & 28.13 \\
\hline E12 & 0.98 & 2.58 & 8.28 & 27.93 \\
\hline E13 & 0.76 & 2.34 & 4.12 & 25.81 \\
\hline E14 & 2.41 & 4.05 & 9.24 & 37.50 \\
\hline E15 & 2.18 & 2.98 & 3.04 & 39.22 \\
\hline E16 & 1.78 & 2.53 & 5.98 & 40.00 \\
\hline E17 & 1.14 & 1.65 & 3.02 & 34.48 \\
\hline E18 & 2.1 & 2.93 & 9.6 & 39.62 \\
\hline
\end{tabular}

Table -8: Calculations for J, V1, V2 \& $\eta$ using L18 orthogonal array

\begin{tabular}{|l|l|l|l|l|}
\hline $\begin{array}{l}\text { Experimental } \\
\text { Number }\end{array}$ & $\begin{array}{l}\text { Heat } \\
\text { input } \\
\text { (J) } \\
\mathrm{kJ} / \mathrm{mm}\end{array}$ & $\begin{array}{l}\text { Weld } \\
\text { Bead } \\
\text { Volume } \\
\text { (V1) } \\
\mathrm{mm} 3\end{array}$ & $\begin{array}{l}\text { Wire } \\
\text { deposition } \\
\text { (V2) } \\
\mathrm{mm} 3\end{array}$ & $\begin{array}{l}\text { Wire } \\
\text { deposition } \\
\text { efficiency }\end{array}$ \\
\hline E01 & 0.84 & 1114 & 1131 & $98.44 \%$ \\
\hline E02 & 0.50 & 3000 & 3080 & $97.40 \%$ \\
\hline E03 & 0.36 & 5880 & 6034 & $97.44 \%$ \\
\hline E04 & 0.58 & 1120 & 1131 & $98.99 \%$ \\
\hline E05 & 0.41 & 2993 & 3080 & $97.16 \%$ \\
\hline E06 & 0.96 & 5906 & 6034 & $97.88 \%$ \\
\hline E07 & 1.08 & 2208 & 2263 & $97.58 \%$ \\
\hline E08 & 0.65 & 4533 & 4620 & $98.11 \%$ \\
\hline E09 & 0.46 & 2005 & 2011 & $99.67 \%$ \\
\hline E10 & 0.36 & 3308 & 3394 & $97.44 \%$ \\
\hline E11 & 0.84 & 1512 & 1540 & $98.18 \%$ \\
\hline E12 & 0.50 & 3938 & 4023 & $97.89 \%$ \\
\hline E13 & 0.41 & 2224 & 2263 & $98.29 \%$ \\
\hline
\end{tabular}

\begin{tabular}{|l|l|l|l|l|}
\hline E14 & 0.96 & 4512 & 4620 & $97.66 \%$ \\
\hline E15 & 0.58 & 1976 & 2011 & $98.25 \%$ \\
\hline E16 & 0.65 & 3375 & 3394 & $99.43 \%$ \\
\hline E17 & 0.46 & 1523 & 1540 & $98.86 \%$ \\
\hline E18 & 1.08 & 3975 & 4023 & $98.81 \%$ \\
\hline
\end{tabular}

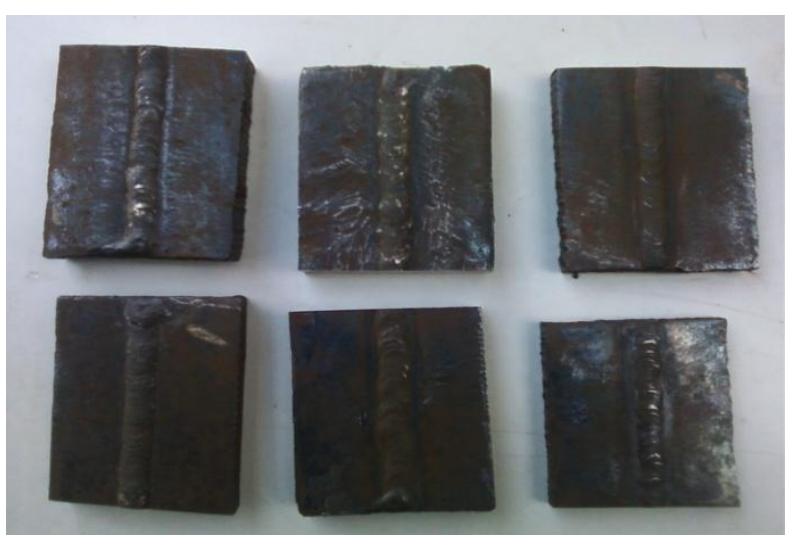

Fig -3: Weld bead on 12mm thickness plates.

\section{ANALYSIS OF VARIANCE (ANOVA)}

\subsection{Analysis of Results for Depth of Penetration}

From the experimental results of the 18 experiments in Table 4, it is observed that the penetration ranges from $0.75 \mathrm{~mm}$ to $2.41 \mathrm{~mm}$. A summary of factor effects is tabulated in Table 7. The penetration value 1.043 is the average of penetrations obtained in the selectively chosen experiments out of the 18 experiments for plate thickness values of $6 \mathrm{~mm}$ which is level 1 for factor A. The other mean penetrations are also obtained in the same way. Delta is the variation of the mean values of penetration within that factor. The effect of factors is ranked as per the magnitude of delta values. The highest ranked factor ' $\mathrm{C}$ ' has the maximum effect followed by $\mathrm{D}, \mathrm{A}, \mathrm{B}$ and $\mathrm{E}$ in order. The factor effects are displayed graphically in Chart - 1, which makes it easy to visualize the relative effects of the various factors on depth of penetration.

Table -9: Mean analysis for depth of penetration.

\begin{tabular}{|l|l|l|l|l|l|}
\hline Level & A & B & C & D & E \\
\hline 1 & 1.043 & 1.103 & 1.163 & 1.697 & 1.298 \\
\hline 2 & 1.622 & 1.432 & 1.303 & 1.430 & 1.362 \\
\hline 3 & 1.645 & 1.775 & 1.843 & 1.183 & 1.650 \\
\hline Delta & 0.602 & 0.672 & 0.680 & 0.513 & 0.352 \\
\hline Rank & 3 & 2 & 1 & 4 & 5 \\
\hline
\end{tabular}




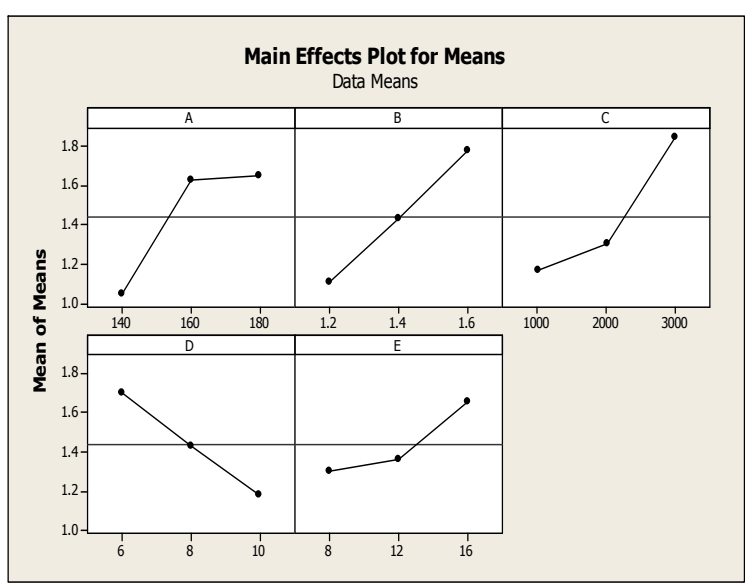

Chart -1: Effect of factor levels on depth of penetration in GTAW.

The following observations are made from the Chart -1 and Table 9

i. Wire feed rate (factor $\mathrm{C}$ ) has the largest effect on depth of penetration. By increasing the feed rate from 1000 $\mathrm{mm} / \mathrm{min}$ to $3000 \mathrm{~mm} / \mathrm{min}$, the depth of penetration can be increased by $0.68 \mathrm{~mm}$.

ii. The wire diameter (factor B) has the next largest effect on depth of penetration. The mean penetration is low at diameter level 1 and high at diameter level 3. The range of change in penetration depth is about $0.672 \mathrm{~mm}$.

iii. Current (factor $\mathrm{A}$ ) has the next effect on the depth of penetration among the factors considered in the present study. The depth of penetration is increasing from level 1 to level 3 is $0.602 \mathrm{~mm}$.

iv. The wire feed rate to travel speed ratio (factor D) has the next largest effect on depth of penetration. Increasing the WFR/TS ratio from 6 to 10 i.e., reducing the travel speed, can improve depth penetration by $0.513 \mathrm{~mm}$.

v. Plate thickness (factor E) little effect on the depth of penetration. The mean depth of penetration is low on 8 $\mathrm{mm}$ plate. Depth of penetration is more on $6 \mathrm{~mm}$ thick plate. The change in penetration depth is about $0.6 \mathrm{~mm}$.

In the present analysis, since the depth of penetration is the response variable, the higher value of quality characteristic is better. Therefore, from the Fig 4, the optimum conditions chosen are A3 B3 C3 D1 E3

\subsection{Analysis of Results for Reinforcement Height.}

It is observed from the results tabulated in Table 7, it is observed that the reinforcement ranges from $1.65 \mathrm{~mm}$ to $4.95 \mathrm{~mm}$. A summary of factor effects is tabulated in Table 10 and the factor effects are displayed graphically in Chart-2, which makes it easy to visualize the relative effects of the various factors on Convexity Index.
Table -10: Mean analysis for reinforcement height.

\begin{tabular}{|l|l|l|l|l|l|}
\hline Level & A & B & C & D & E \\
\hline 1 & 2.662 & 2.247 & 2.153 & 3.183 & 2.797 \\
\hline 2 & 3.280 & 2.762 & 2.678 & 2.572 & 2.542 \\
\hline 3 & 2.513 & 3.447 & 3.623 & 2.700 & 3.117 \\
\hline Delta & 0.767 & 1.200 & 1.470 & 0.612 & 0.575 \\
\hline Rank & 3 & 2 & 1 & 4 & 5 \\
\hline
\end{tabular}

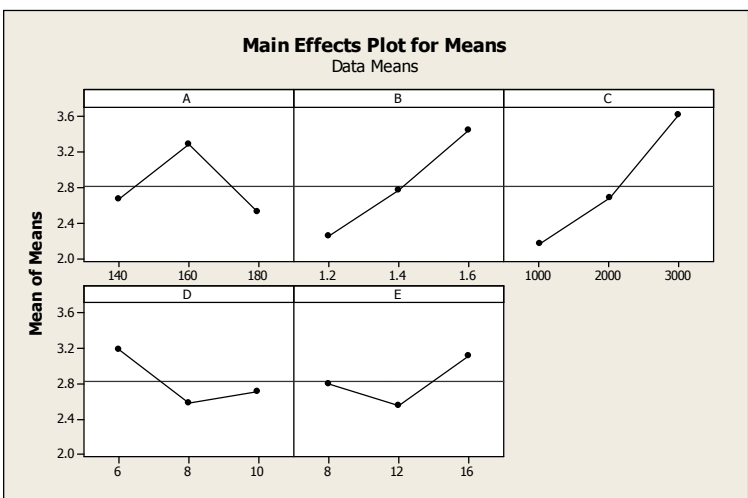

Chart -2: Effect of factor levels on reinforcement height in GTAW.

The following observations are made from the Chart -2 and Table 10

i. Wire feed rate (factor $\mathrm{C}$ ) has the largest effect on reinforcement. By increasing the feed rate from 1000 $\mathrm{mm} / \mathrm{min}$ to $3000 \mathrm{~mm} / \mathrm{min}$, the reinforcement can be increased by $1.47 \mathrm{~mm}$.

ii. The wire diameter (factor B) has the next largest effect on depth of reinforcement. By the increasing the wire diameter from $1.2 \mathrm{~mm}$ to $1.6 \mathrm{~mm}$, the reinforcement can be increased by $1.2 \mathrm{~mm}$.

iii. Current (factor A) has the next effect on the reinforcement among the factors considered in the present study. The mean reinforcement is low at current level 3 and high at current level 1. The range of change in penetration depth is about $0.767 \mathrm{~mm}$.

iv. The wire feed rate to travel speed ratio (factor D) has the next largest effect on reinforcement. Increasing the WFR/TS ratio from 6 to 10 i.e., reducing the travel speed, can decrease reinforcement by $0.612 \mathrm{~mm}$.

v. Plate thickness (factor E) little effect on the depth of penetration. The mean reinforcement is low on $8 \mathrm{~mm}$ plate. Reinforcement is more on $12 \mathrm{~mm}$ thick plate. The change in reinforcement is about $0.5 \mathrm{~mm}$.

In the present analysis, since the depth of penetration is the response variable, the higher value of quality characteristic is better. Therefore, from the Fig 5, the optimum conditions chosen are A2 B3 C3 D1 E3. 


\subsection{Analysis of Results for Bead Width.}

From the experimental results of the 18 experiments in Table 7, it is observed that the bead width ranges from $3.02 \mathrm{~mm}$ to $10.4 \mathrm{~mm}$. A summary of factor effects is tabulated in Table 11. The bead width value 6.574 is the average of bead width obtained in the selectively chosen experiments out of the 18 experiments for current value of $140 \mathrm{~A}$ which is level 1 for factor A. The other mean bead widths are also obtained in the same way. Delta is the variation of the mean values of bead width within that factor. The effect of factors is ranked as per the magnitude of delta values. The highest ranked factor ' $\mathrm{D}$ ' has the maximum effect followed by $\mathrm{C}$, E, B and A in order. The factor effects are displayed graphically in Chart -3 , which makes it easy to visualize the relative effects of the various factors on bead width.

Table -11: Mean analysis for bead width

\begin{tabular}{|l|l|l|l|l|l|}
\hline Level & A & B & C & D & E \\
\hline 1 & 6.547 & 5.340 & 4.025 & 7.870 & 6.390 \\
\hline 2 & 5.642 & 6.175 & 6.595 & 5.865 & 6.653 \\
\hline 3 & 0.905 & 1.240 & 3.450 & 3.510 & 1.602 \\
\hline Rank & 5 & 4 & 2 & 1 & 3 \\
\hline
\end{tabular}

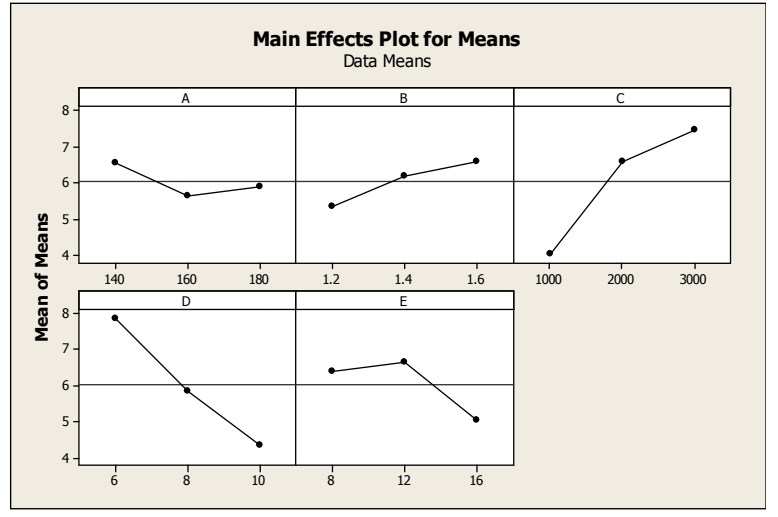

Chart -3: Effect of factor levels on bead width in GTAW.

The following observations are made from the Chart -3 and Table 11

i. The wire feed rate to travel speed ratio (factor D) has the largest effect on bead width. Increasing the WFR/TS ratio from 6 to 10 i.e., reducing the travel speed, can decrease the bead width by $3.51 \mathrm{~mm}$.

ii. Wire feed rate (factor $\mathrm{C}$ ) has the next largest effect on bead width. By increasing the feed rate from 1000 $\mathrm{mm} / \mathrm{min}$ to $3000 \mathrm{~mm} / \mathrm{min}$, the bead width can be increased by $3.45 \mathrm{~mm}$.

iii. The wire diameter (factor B) has the next largest effect on bead width. The bead width is increasing from level 1 to level 3 is $0.602 \mathrm{~mm}$.

iv. Current (factor A) has the next effect on the bead width among the factors considered in the present study. The mean width is high at diameter level 1 and low at diameter level 2. The range of change in bead width is about $1.24 \mathrm{~mm}$.

v. Plate thickness (factor E) little effect on the bead width. The mean width is high on $12 \mathrm{~mm}$ plate. Bead width is more on $16 \mathrm{~mm}$ thick plate. The change in width is about $1.6 \mathrm{~mm}$.

In the present analysis, since the bead width is the response variable, the higher value of quality characteristic is better. Therefore, from the Fig 6, the optimum conditions chosen are A1 B3 C3 D1 E2.

\subsection{Development of Mathematical Models.}

The experimental results that are given in previous section are used to obtain the mathematical relationship between process parameters and bead geometry. The coefficients of mathematical models are computed by using method of multiple regressions. A commercial software Datafit has been used for the regression analysis. This software is used to test several models viz., linear, exponential, power series (user defined). Out of all models tested the model that has high coefficient of multiple determination (R2) value and better t-ratio is chosen. The adequacy of the models and the significance of coefficients are tested by applying analysis of variance and student $(\mathrm{T})$ test.

The relationship between penetration (or reinforcement or width ) as response variable(s) and to give process parameters viz., current, wire diameter, wire feed rate, WFR/TS ratio \& plate thickness as independent parameters can be expressed as

$$
\mathrm{Y}=10^{\mathrm{a}} \mathrm{X}_{1}^{\mathrm{b}} \mathrm{X}_{2}^{\mathrm{c}} \mathrm{X}_{3}^{\mathrm{d}} \mathrm{X}_{4}^{\mathrm{e}} \mathrm{X}_{5}^{\mathrm{f}}
$$

Where $\mathrm{Y}$ is the penetration in $\mathrm{mm}$, or convexity index

$$
\begin{array}{lc}
\mathrm{X}_{1} \text { - current, } \mathrm{A} & \text { (factor } \mathrm{A} \text { ) } \\
\mathrm{X}_{2}-\text { wire diameter, } \mathrm{mm} & \text { (factor B) } \\
\mathrm{X}_{3} \text { - wire feed rate, } \mathrm{m} / \mathrm{min} & \text { (factor C) } \\
\mathrm{X}_{4}-\text { wire feed rate/travel speed ratio (factor D) } \\
\mathrm{X}_{5}-\text { plate thickness, mm } & \text { (factor } \mathrm{E} \text { ) } \\
\multicolumn{2}{c}{\mathrm{a}, \mathrm{b}, \mathrm{c}, \mathrm{d}, \mathrm{e} \text { and } \mathrm{f} \text { - regression variables }}
\end{array}
$$

The multiple regression analysis resulted the following equations Penetration
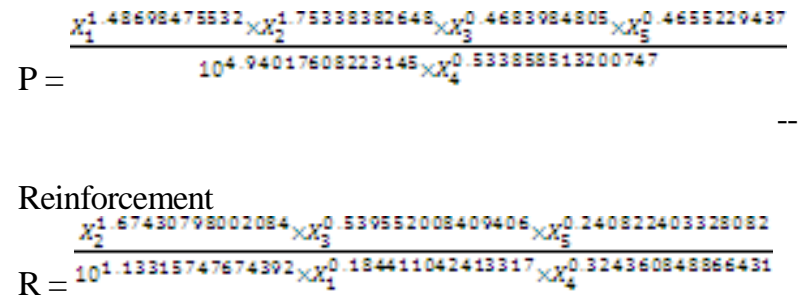
Width

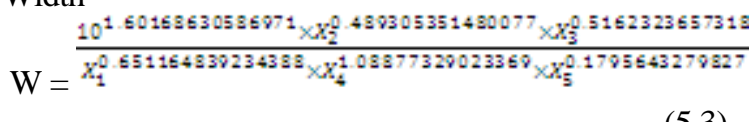

Regression analysis results are presented in Table 11 for depth of penetration. The adequacy of the each model is tested by the analysis of variance (ANOVA). Table 12 shows the ANOVA for penetration.

Model Definition: Penetration

$\mathrm{Y}=10^{\wedge} \mathrm{a}^{*} \mathrm{x} 1^{\wedge} \mathrm{b}^{*} \mathrm{x} 2^{\wedge} \mathrm{c}^{*} \mathrm{x} 3^{\wedge} \mathrm{d}^{*} \mathrm{x} 4^{\wedge} \mathrm{e}^{*} \mathrm{x} 5^{\wedge} \mathrm{f}$

Number of observations $=18$

Number of missing observations $=0$

Solver type: Nonlinear

Nonlinear iteration limit $=250$

Diverging nonlinear iteration limit $=10$

Number of nonlinear iterations performed $=27$

Residual tolerance $=0.0000000001$

Sum of Residuals $=-4.37332326231613 \mathrm{E}-02$

Average Residual $=-2.42962403462007 \mathrm{E}-03$

Residual Sum of Squares (Absolute) $=1.22954527201257$

Residual Sum of Squares (Relative) $=1.22954527201257$

Standard Error of the Estimate $=0.320097025917216$

Coefficient of Multiple Determination $\left(\mathrm{R}^{\wedge} 2\right)=0.7963047493$

Proportion of Variance Explained $=79.63047493 \%$

Adjusted coefficient of multiple determination $\left(\mathrm{Ra}^{\wedge} 2\right)=$

0.7114317282

Durbin-Watson statistic $=1.59153398914335$

99\% Confidence Intervals

Variable Value

$\begin{array}{ll}\text { a } & -4.94017608223145 \\ \text { b } & 1.48698475532579 \\ \text { c } & 1.75338382648395 \\ \text { d } & 0.468398480585137 \\ \text { e } & -0.533858513200747 \\ \text { f } & 0.465522943706036\end{array}$

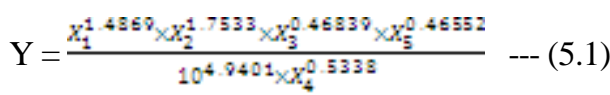

Table -12: Analysis of Variance for depth of penetration model

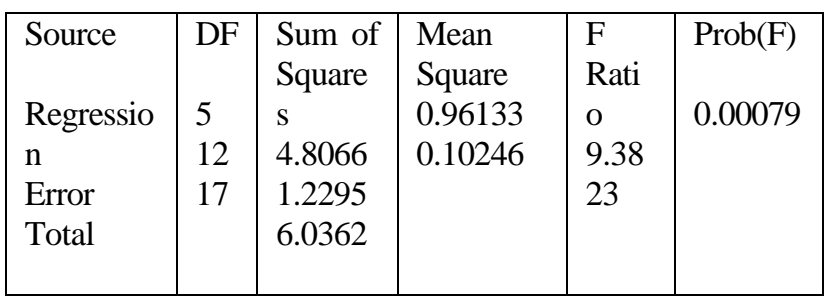

Chart -4 shows the relationship between experimental value and predicted value of depth of penetration in Gas Tungsten Arc Welding. It is observed from the Chart -4 that the values predicted by penetration model (Eqn. 5.1) are in good agreement with experimental values. The experimental and predicted values of penetration and percentage error are given in Table 13. It can be observed from the table that the percentage error is less than $29 \%$ in all the cases except one. Hence it is concluded that the model can predict the depth of penetration in GTAW with good accuracy.

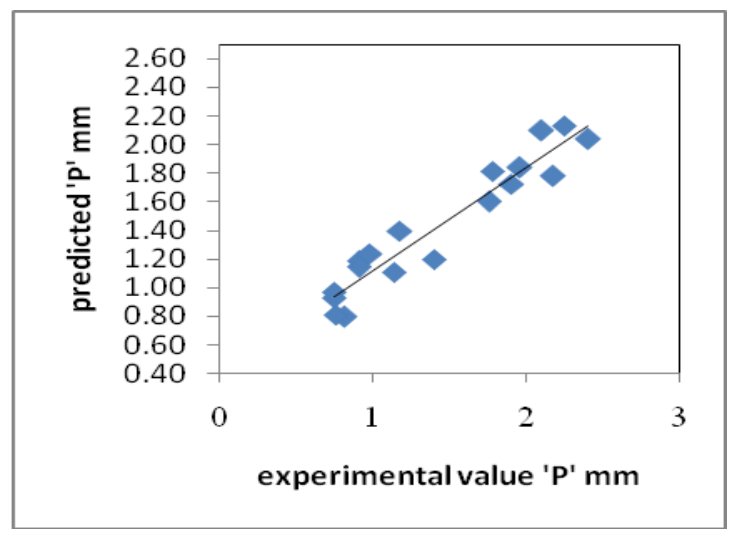

Chart-4: Results based on experimental and predicted values of penetration.

Table -13: Comparison between predicted value and experimental value of penetration in GTAW

\begin{tabular}{|l|l|l|l|l|}
\hline $\begin{array}{l}\text { Exp. } \\
\text { No. }\end{array}$ & $\begin{array}{l}\text { Penetratio } \\
\mathrm{n}(\mathrm{P}) \mathrm{mm}\end{array}$ & $\begin{array}{l}\text { Calculate } \\
\mathrm{d}(\mathrm{P})\end{array}$ & Residual & $\begin{array}{l}\% \\
\text { Error }\end{array}$ \\
\hline E01 & 0.75 & 0.63 & -0.12 & -15.85 \\
\hline E02 & 0.91 & 1.19 & 0.28 & 30.23 \\
\hline E03 & 1.96 & 1.84 & -0.12 & -6.22 \\
\hline E04 & 0.82 & 0.80 & -0.02 & -2.77 \\
\hline E05 & 1.31 & 1.47 & 0.16 & 11.98 \\
\hline E06 & 2.25 & 2.13 & -0.12 & -5.22 \\
\hline E07 & 1.76 & 1.75 & -0.01 & -0.45 \\
\hline E08 & 1.91 & 1.72 & -0.19 & -9.73 \\
\hline E09 & 1.18 & 1.40 & 0.22 & 18.34 \\
\hline E10 & 0.75 & 0.97 & 0.22 & 29.44 \\
\hline E11 & 0.91 & 1.14 & 0.23 & 25.48 \\
\hline E12 & 0.98 & 1.24 & 0.26 & 26.54 \\
\hline E13 & 0.76 & 0.81 & 0.05 & 6.68 \\
\hline E14 & 2.41 & 2.04 & -0.37 & -15.44 \\
\hline E15 & 2.18 & 1.51 & -0.67 & -30.76 \\
\hline E16 & 1.78 & 1.82 & 0.04 & 2.07 \\
\hline E17 & 1.14 & 0.91 & -0.23 & -19.75 \\
\hline E18 & 2.1 & 2.54 & 0.44 & 20.84 \\
\hline
\end{tabular}


So the values of current and wire diameter are taken as $180 \mathrm{~A}$ and $1.6 \mathrm{~mm}$ respectively for plotting predicted the depth of penetration at different wire feed rates, WFR/TS ratio and on different plate thickness. It is observed from the plots that the depth of penetration increases with increase in wire feed rate or increase in welding speed (i.e., increase in WFR/TS ratio) for a given plate thickness. This is because at high wire feed rate the heat input is more and hence more depth of penetration. are useful to predict the depth of penetration at different wire feed rates and at different WFR/TS ratio.

\section{CONCLUSIONS}

1. From the present work the mathematical models were developed for penetration, reinforcement and width.

2. Compression had made between the experimental values and predicted values (by using generated formulas) are showing reasonable agreement.

\section{REFERENCES}

[1] I.S. Kim, J.S. Son, H.J. Kim and B.A. Chin, "A study on variation of shielding gas in GTA welding using finite element method", AMME Volume 17, issue 1-2, pp. 249-252, July - august 2006.

[2] Y. S. Tarng and W. H. Yang Yang "Optimization of the Weld Bead Geometry in Gas Tungsten Arc Welding by the Taguchi Method". The International| Journal of advanced Manufacturing Technology, pp. 549 - 554, 1998.

[3] Dr Sun Zheng, Dr Kuo Min and Pan Dayou, "Twin Wire Gas Tungsten Arc Cladding”, Joining Technology Group, Process Technology Division, 1999.

[4] Bernard Mannion and Jack Heinzman "Determining parameters for GTAW", July/August 1999 issue of Practical Welding Today.

[5] S. X. Lv*, Z. W. Xu, H. T. Wang and S. Q. Yang "Investigation on TIG cladding of copper alloy on steel plate", Science and Technology of Welding and Joining, Volume 13, pp. 10-16, 2008.

[6] T.Jayananda Kumar, "Effect of input current on dilution in claddings produced by gtaw process",

[7] AWS Welding Handbook, $8^{\text {th }}$ Edition.

[8] The Welding Institute Journal, 175/1982, Study of Welding Process Prameters.

[9] The Welding Institute Journal, 283/1985, Dilution.

[10] “Modern Arc Welding Technology" By S.V. Nadkarni.

[11] "Metals Handbook, $8^{\text {th }}$ Edition, Vol-1" Properties and selection of metals of American society for metals.

[12] “Materials Handbook” By AWS.

[13] "The Procedure Handbook of Arc Welding" $12^{\text {th }}$ Edition, By Lincoln.

[14] “Mechanical Metallurgy” By Linnert.

\section{BIOGRAPHIES}

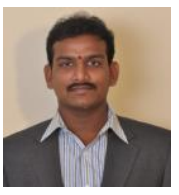

Mr. K. Ashok Kumar working as an Assistant Professor in the Department of Mechanical Engineering at Shri Vishnu Engineering College for Women, Bhimavaram. Mr. K.Ashok Kumar obtained his B.E first class at TJIT, Channai, M.Tech first class with distinction from GIET, Rajahmundry and have 1 year industrial and 2 years teaching experience.

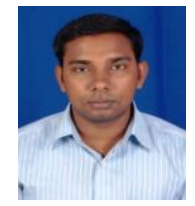

Mr. G. Satish working as an Assistant Professor in the Department of Mechanical Engineering at Shri Vishnu Engineering College for Women, Bhimavaram and obtained his B.Tech and M.Tech(Machine Design) degrees both with first class at JNTUK. He has experience of 2 years as CAD engineer and 2years teaching and published 1 international journal.

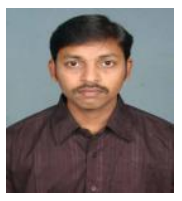

Mr. V. Lakshmi Narayana working as an Assistant Professor in the Department of Mechanical Engineering at Shri Vishnu Engineering College for Women, Bhimavaram. He has completed his B.Tech in the discipline of Mechanical and M.Tech in CAD/CAM. He did both degrees in first class with distinction. He has work experience of 1 year as CAD Engineer and 4 years as an Assistant Professor.

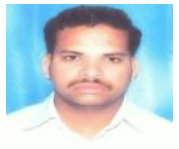

Mr. N. Srinivasa Rao working as an Assistant Professor in the Department of Mechanical Engineering at Shri Vishnu Engineering College for Women, Bhimavaram. He has completed his B.Tech in the discipline of Mechanical and M.Tech in Automobile Engineering in NIT Warangal. He did both degrees in first class. He has 3 years as an Assistant Professor in teaching. 